\title{
Right ventricular load adaptability metrics in patients undergoing left ventricular assist device implantation
}

Myriam Amsallem, MD, MS, ${ }^{\text {a,b,c }}$ Marie Aymami, MD, MS, ${ }^{\text {a,b,d } W i l l i a m ~ H i e s i n g e r, ~ M D, ~}$ Sanford Zeigler, MD, ${ }^{\mathrm{e}}$ Kegan Moneghetti, MD, ${ }^{\mathrm{a}, \mathrm{b}}$ Michael Marques, MD, PhD, Jeffrey Teuteberg, MD, PhD, ${ }^{a, b}$ Richard Ha, MD, ${ }^{e}$ Dipanjan Banerjee, MD, ${ }^{a, b}$ and François Haddad, MD $^{\mathrm{a}, \mathrm{b}}$

\section{ABSTRACT}

Objective: Several right load adaptability metrics have been proposed as predictors of right heart failure (RHF) following left ventricular assist device implantation. This study sought to validate and compare the prognostic value of these indices.

Methods: This retrospective study included 194 patients undergoing continuousflow left ventricular assist device implantation. The primary end point was unplanned right atrial assist device (RVAD) need within 30 days after left ventricular assist device implantation; the secondary end points included clinical RHF syndrome without RVAD need and the composite of RHF or RVAD need. Load adaptability indices or interventricular ratios were divided into surrogates of ventriculoarterial coupling (RV area change:end-systolic area), indices reflecting adaptation proportionality (Dandel's index = tricuspid regurgitation velocitytime integral normalized for average RV radius in diastole or systole), and simple ratios (eg, pulse pressure:right atrial pressure or right arterial pressure:pulmonary arterial wedge pressure).

Results: Mean age was $55 \pm 13$ years with $77 \%$ of men. RHF occurred in 75 patients with 30 patients requiring RVAD implantation. Among right heart metrics, right arterial pressure (normalized odd ratio, 1.62; 95\% confidence interval, 1.152.38), right arterial pressure:pulmonary arterial wedge pressure (normalized odds ratio, $1.59 ; 95 \%$ confidence interval, 1.08-2.32) and pulse pressure:right arterial pressure $<2.0$ (normalized odds ratio, 2.56; 95\% confidence interval, 1.16-5.56) were associated with RVAD need (all $P$ values $<.02$ ). These 3 metrics significantly added incremental prognostic value to the Interagency Registry for Mechanically Assisted Circulatory Support classification score in a similar range, whereas only RAP was incremental to the Michigan score. Correlates of RHF not requiring RVAD included RV end-systolic area index and the Dandel indices, which provided similar incremental value to the Interagency Registry for Mechanically Assisted Circulatory Support, Michigan, and European Registry for Patients with Mechanical Circulatory Support scores.

Conclusions: Although associated with outcome, right load adaptability indices do not appear to provide strong incremental value when compared with simple metrics. (J Thorac Cardiovasc Surg 2019;157:1023-33)

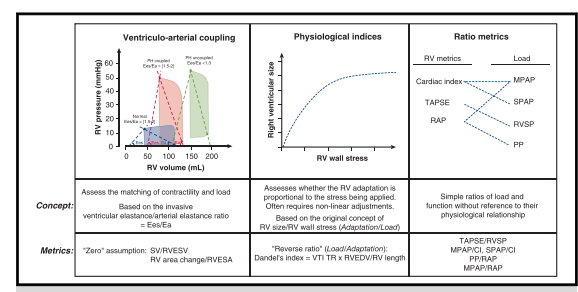

Concepts behind right heart load adaptability.

Central Message

Right load adaptability metrics provide similar prognostic value to simple metrics such as right atrial pressure or right ventricular end-systolic size for prediction of right heart failure postLVAD.

\section{Perspective}

Integrating both invasive and non-invasive right heart metrics, this study contributes to the simplification of prognostic markers of right heart failure after continuous-flow LVAD implantation. Our findings highlight the strong prognostic value of right atrial pressure for prediction of RVAD need post-LVAD and of right ventricular end-systolic dimensions for prediction of clinical right heart failure not requiring RVAD

See Commentaries on pages 1034 and 1036.

\footnotetext{
From the Divisions of ${ }^{\mathrm{a}}$ Cardiovascular Medicine, ${ }^{\mathrm{e}}$ Cardiothoracic Surgery, and ${ }^{\mathrm{f}}$ Anesthesiology, and ${ }^{\mathrm{b}}$ Stanford Cardiovascular Institute, Stanford University School of Medicine, Stanford, Calif; ${ }^{\mathrm{c}}$ Research and Innovation Unit, INSERM U999, DHU TORINO, Paris Sud University, Marie Lannelongue Hospital, Le Plessis Robinson, France; and ${ }^{\mathrm{d}}$ Division of Cardiac, Thoracic, and Vascular Surgery, University Hospital of Rennes, Rennes, France.

Dr Amsallem received a Young Investigator Seed Grant from the Vera Moulton Wall Center at Stanford University and is supported by a public grant overseen by the French National Research Agency as part of the second Investissement d'Avenir program (ANR-15-RHUS-0002). Dr Aymami received a grant from the French Federation of Cardiology. Dr Haddad received funds from the Pai Chan Lee
}

Research fund. None of the sponsors participated in the study design, collecting, analyzing, and interpreting the data, writing the report, or deciding whether and where to submit the report for publication.

Received for publication April 19, 2018; revisions received July 31, 2018; accepted for publication Aug 10, 2018; available ahead of print Oct 25, 2018.

Address for reprints: Myriam Amsallem, MD, MS, Stanford University School of Medicine, 300 Pasteur Dr, Stanford, CA 94304 (E-mail: mamsalle@stanford.edu). $0022-5223 / \$ 36.00$

Copyright $(2018$ by The American Association for Thoracic Surgery

https://doi.org/10.1016/j.jtcvs.2018.08.095 


\section{Abbreviations and Acronyms \\ EUROMACS $=$ European Registry for Patients with Mechanical Circulatory Support \\ INTERMACS $=$ Interagency Registry for Mechanically Assisted Circulatory Support \\ LVAD $=$ left ventricular assist device \\ MPAP $=$ mean pulmonary arterial pressure \\ PAWP $=$ pulmonary arterial wedge pressure \\ $\mathrm{PP} \quad=$ pulse pressure \\ RAP $=$ right atrial pressure \\ RHF $\quad=$ right heart failure \\ RV = right ventricular \\ RVAD = right ventricular assist device \\ RVESAI = right ventricular end-systolic area index \\ RVSP $=$ right ventricular systolic pressure \\ SPAP $\quad=$ systolic pulmonary arterial pressure \\ TAPSE $\quad=$ tricuspid annular plane systolic excursion}

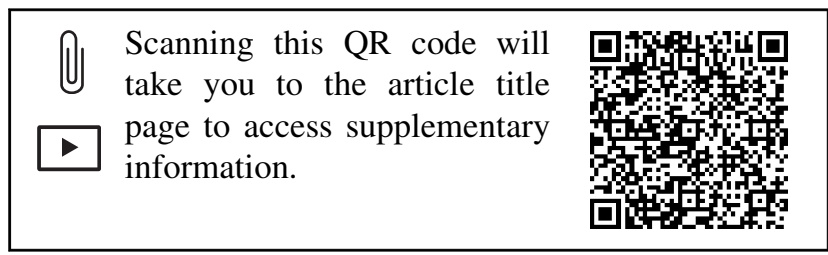

Right heart failure (RHF) represents a major complication following continuous-flow left ventricular assist device (LVAD) implantation leading to high morbi-mortality. ${ }^{1-4}$ Because predicting RHF remains challenging, ${ }^{5}$ several studies have explored hemodynamic or echocardiographic indices of right heart load adaptability. ${ }^{6-9}$

Right load adaptability refers to different concepts, as illustrated in Figure $1 .{ }^{10}$ The first concept, ventriculoarterial coupling, is usually measured as the ratio of ventricular to arterial elastance using invasive pressure-volume analysis. ${ }^{11}$ Approximations have been proposed, such as the stroke volume to end-systolic volume ratio, assuming that volume at pressure 0 passes through the origin. ${ }^{12}$ The second concept assesses whether ventricular dysfunction or enlargement is proportional or not to the load imposed on it. It is based on the concept of the proportionality of right ventricular (RV) remodeling to wall stress. ${ }^{6,10}$ The third category includes ratios of function and load metrics, such as the tricuspid annular plane systolic excursion to RV systolic pressure ratio (TAPSE:RVSP), which fails to take into account the physiologic dependence of load and function. ${ }^{7,13}$

The analysis of the prognostic value of load adaptability metrics has often been limited to single-center studies with limited external validation. Furthermore, few LVAD studies have compared them with simple RV remodeling or functional metrics (such as RV end-systolic dimension or strain), or to invasive interventricular ratios such as the right atrial to pulmonary arterial wedge pressure ratio (RAP:PAWP) validated in the large European Registry for Patients with Mechanical Circulatory Support (EUROMACS) study., We recently compared the prognostic value of load adaptability metrics in patients with pulmonary arterial hypertension, showing that they were not stronger predictor of clinical worsening than RV end-systolic dimension. ${ }^{10}$ In the present study, we hypothesized that in patients with an LVAD the prognostic value of load adaptability metrics for RHF may have limited incremental value to validated risk scores when compared with simple metrics of $\mathrm{RV}$ remodeling or function.

Using the Stanford LVAD prospective registry, the first objective was to determine the prognostic value of load adaptability and interventricular metrics for the risk of right ventricular assist device (RVAD) need (primary end point) or clinical RHF without RVAD (secondary end point) or composite end point of RHF or RVAD need (secondary end point) after LVAD implantation. The second objective was to compare their incremental prognostic value to validated risk scores (such as the EUROMACS score, Michigan score, ${ }^{14}$ and Interagency Registry for Mechanically Assisted Circulatory Support [INTERMACS] profiles) to those of simple invasive or imaging metrics.

\section{METHODS}

\section{Study Population}

This retrospective study screened 230 consecutive patients (aged $>18$ years) from the Stanford prospective LVAD registry who underwent continuous-flow LVAD implantation at Stanford University Medical Center between January 2009 and June 2016. Inclusion criteria were patients with left heart failure requiring LVAD implantation with echocardiographic and right heart catheterization data available within 3 months before implantation. Exclusion criteria were complete echocardiographic study not available for review $(\mathrm{n}=19)$, data from right heart catheterization performed at other centers not available $(n=15)$, and planned RVAD implantation $(n=2)$. Isolated LVAD implantations were done under cardiopulmonary bypass on a beating heart. Combined surgeries involved total aortic crossclamping and cardioplegic cardiac arrest except for 7 out of 8 tricuspid valve repair procedures. Postoperative inotropic and vasopressor support (using milrinone, dobutamine, epinephrine, and/or vasopressin) was at the discretion of the physicians, targeting a central venous pressure $<15 \mathrm{~mm} \mathrm{Hg}$ and cardiac index $>2 \mathrm{~L} / \mathrm{min} / \mathrm{m}^{2}$ in the operating room and during the postoperative phase. In the intensive care unit, vasopressor and pulmonary vasodilator supports were weaned as the heart recovered, based on invasive monitoring. A mean arterial pressure of 65 to $90 \mathrm{~mm} \mathrm{Hg}$ was targeted to support renal perfusion with a central venous pressure $<15 \mathrm{~mm} \mathrm{Hg}$ while maintaining a cardiac index $>2 \mathrm{~L} / \mathrm{min} / \mathrm{m}^{2}$. The Stanford University Institutional Review Board approved the study 


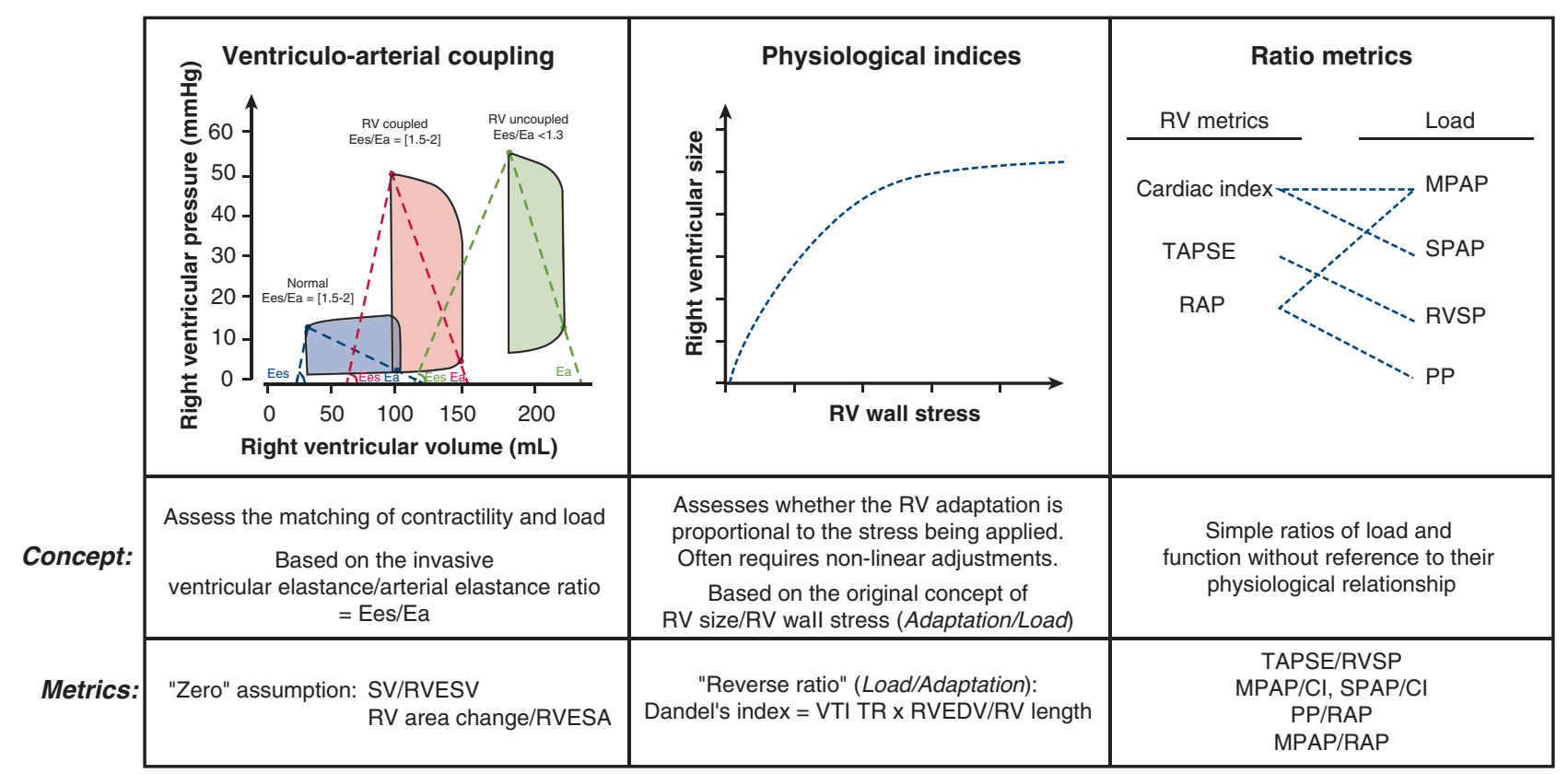

FIGURE 1. Load adaptation indices and concepts. $R V$, Right ventricular; Ees, ventricular elastance; $E a$, arterial elastance; $S V$, stroke volume; $R V E S V$, RV end-systolic volume; RVESA, RV end-systolic area; VTI TR, velocity time integral using continuous Doppler signal of the tricuspid regurgitation; $R V E D V$, RV end-diastolic volume; MPAP, mean pulmonary arterial pressure; TAPSE, tricuspid annular plane systolic excursion; SPAP, systolic pulmonary arterial pressure; $R A P$, right atrial pressure; $R V S P$, right ventricular systolic pressure; $P P$, pulse pressure; $C I$, cardiac index. Adapted with permission from Stanford Clinical Biomarker and Phenotype Core Laboratory.

(No. 25673), which was conducted in agreement with the Helsinki-II declaration; all patients gave informed consent.

\section{Echocardiography}

Echocardiograms, performed within 2 months of LVAD implantation and within a week for $59 \%$ of patients, were acquired using Philips IE33 ultrasound systems (Philips, Amsterdam, The Netherlands). All measures were averaged over 3 cycles and analyzed according to the latest guidelines by 2 blinded certified readers. ${ }^{15}$ Cardiac chambers dimensions, obtained from the apical 4-chamber view at end-diastole and end-systole, included $\mathrm{RV}$ areas (RV end-diastolic area index and RV end-systolic area index [RVESAI]) and right atrial maximal area indexed to body surface area. RV function was quantified using fractional area change, TAPSE, and free-wall Lagrangian longitudinal strain. Free-wall Lagrangian longitudinal strain was measured from mid-endocardial end-diastolic and end-systolic manually traced lengths and calculated as (end-systolic length-end-diastolic length):end-diastolic length. RV systolic pressure was estimated from the tricuspid regurgitation maximal velocity and estimated RAP. ${ }^{16}$

\section{Right Heart Catheterization}

Right heart catheterization within 3 months of inclusion (within a week for $60 \%$ of patients) was performed through the right internal jugular or femoral vein. Afterload was assessed by mean pulmonary arterial pressure (MPAP), relative pressure (MPAP:mean arterial pressure), ${ }^{17}$ systolic (SPAP) and diastolic pulmonary arterial pressures, pulmonary vascular resistance, capacitance, and arterial elastance. Pulmonary vascular resistance index was measured as transpulmonary gradient divided by cardiac index. Capacitance was estimated as stroke volume divided by pulse pressure (PP) (difference between systolic and diastolic pulmonary arterial pressure $)^{18}$ and indexed to body surface area. Pulmonary arterial elastance was defined as SPAP $\times 0.9$ divided by stroke volume. ${ }^{19}$ PAWP was measured at the end of expiration; cardiac output was determined using the thermodilution method (or Fick method in case of severe tricuspid regurgitation), and RAP was averaged over 5 cardiac cycles. RAP:PAWP was calculated. ${ }^{9}$ Preoperative catheterizations and echocardiograms were not routinely repeated the day before surgery if the patient's clinical status was deemed unchanged compared with baseline. The mean time delay between catheterization and echocardiography was $17.5 \pm 25.0$ days; $28 \%$ of the cohort underwent the 2 investigations within 1 day.

\section{Load Adaptability Indices}

The following load adaptability indices were assessed (Figure 1). RV area change:RV end-systolic area was measured similar to the stroke volume:end-systolic volume, a surrogate of the ventricular to arterial elastance ratio. Physiologic indices included the Dandel index as the velocity-time integral of the tricuspid regurgitation signal normalized for the average RV radius described in end-diastole (velocity-time integral of the tricuspid regurgitation signal $\times \mathrm{RV}$ end diastole length:RV end-diastolic area) and the systolic Dandel index using the same formula in end-systole. ${ }^{6}$ Ratio metrics included TAPSE:RVSP, ${ }^{7}$ SPAP:cardiac index, ${ }^{20}$ MPAP:cardiac index, pulmonary artery pulsatility index (PP:RAP),${ }^{13}$ and MPAP:RAP.

\section{Outcomes}

Patients were prospectively followed after enrolment in the registry; follow-up was concluded during September 2016. The primary end point was unplanned need for RVAD occurring $<30$ days post-LVAD. The secondary end points included $<30$ days clinical RHF in patients not requiring RVAD implantation and the composite outcome of $<30$ days clinical RHF or RVAD need post-LVAD. Clinical RHF was defined according to the 2016 INTERMACS definition ${ }^{3}$ as symptoms or findings of persistent RV failure characterized by both of the following: documentation of elevated central venous pressure (direct invasive measurement with evidence of a central venous pressure or RAP $>16 \mathrm{~mm} \mathrm{Hg}$, or findings of significantly dilated inferior vena cava with absence of inspiratory variation by 
echocardiography, or clinical findings of elevated jugular venous distension) and manifestations of elevated central venous pressure (ie, peripheral edema, ascites, or palpable hepatomegaly on physical examination or by diagnostic imaging or laboratory evidence of worsening hepatic [total bilirubin $>2.0 \mathrm{mg} / \mathrm{dL}$ ] or renal dysfunction [creatinine $>2.0 \mathrm{mg} / \mathrm{dL}$ ]). Clinical RHF was retrospectively verified through chart review by 2 independent investigators, and in case of discrepancy between investigators a third investigator helped decide the allocation. Because inhaled nitric oxide was often prophylactically used at our institution, it could not be used to define RHF. All-cause mortality was verified through chart review, follow-up, and the National Social Security Death Index; heart transplantation was verified through chart review and follow-up.

\section{Statistical Analysis}

Statistical analyses were performed using SPSS version 23.0 (IBMSPSS Inc, Armonk, NY). Continuous variables are summarized as mean \pm standard deviation following the central limit theorem for the total population. Categorical variables are presented as number ( $\%)$. Normality was tested using the Shapiro-Wilk test. Comparisons between groups were performed using 1-way variance analysis for continuous variables and $\chi^{2}$ test for categorical data. Pearson correlation coefficients $(r)$ were used to express the correlation between hemodynamic or echocardiographic indices. Survival estimates were based on the Kaplan-Meier method and compared by log-rank statistics. Patients who underwent heart transplant were right-censored on the transplant day and considered as alive. Logistic regression analyses were performed on preoperative variables to identify correlates of the primary end point $(<30$ days RVAD need) or secondary end points $(<30$ days clinical RHF excluding those requiring RVAD or composite end point of RVAD need or RHF) as all events occurred within 3 weeks of LVAD implantation, with a majority (77\% of RVAD) occurring within 72 hours. For continuous variables that were not linearly associated with the logit of the outcome, previously validated thresholds were used (PP:RAP < 2.0).$^{13}$ Because no threshold has been published for MPAP to RAP ratio and it is strongly collinear to PP:RAP, the threshold $<2.5$ corresponding to PP:RAP $<2.0$ was used. For metrics relying on an interpretable tricuspid regurgitation signal (TAPSE:RVSP and the Dandel indices), logistic regression models were performed in patients in whom these indices were determined. Odds ratios (ORs) of continuous variables are presented per unit of the variable and per standard deviation increase or decrease for comparison purposes. Receiver operating characteristic curves were constructed to estimate the area under the curve of indices with $95 \%$ confidence interval (CI) using RVAD need, clinical RHF, or the composite end point as the binary outcome. The incremental value of right heart metrics or load adaptability indices to INTERMACS profiles, the Michigan score, and EUROMACS score (Table E1) was assessed using multivariate logistic regression and comparing $\chi^{2}$ values.

\section{RESULTS}

In total, 194 patients were included (presented in Figure 2): 107 underwent Heartmate II (Thoratec, Calif) placement, 79 had HeartWare HVAD System devices implanted (Heartware, Mass), 7 had Jarvik 2000 devices implanted (Jarvik Heart Inc, New York, NY), and 1 patient underwent HeartAssist5 (ReliantHeart, Houston, Tex) implantation. Mean age was $55 \pm 13$ years, with $77 \%$ of men (Table 1). Thirty-three percent of LVAD implantations were for ischemic cardiomyopathy and $37 \%$ as a destination therapy. The majority of patients left the operating room with inotropic $(95 \%)$ or vasopressor $(96 \%)$ support, and about one-third were still receiving support 10 days post-LVAD implantation (39\% for inotropes and 30\% for vasopresssors).

Our cohort confirmed the strong linear correlation between preoperative MPAP and SPAP $(r=0.93)$ and the moderate linear correlation between $\mathrm{PP}$ and MPAP $(r=0.61$ ), both $P$ values $<.0001$ (Figure 3, A). Similarly, Figure $3, B$, illustrates the overlap between RAP and RAP:PAWP. Although most of patients with elevated RAP:PAWP had also elevated RAP, there were 14 patients

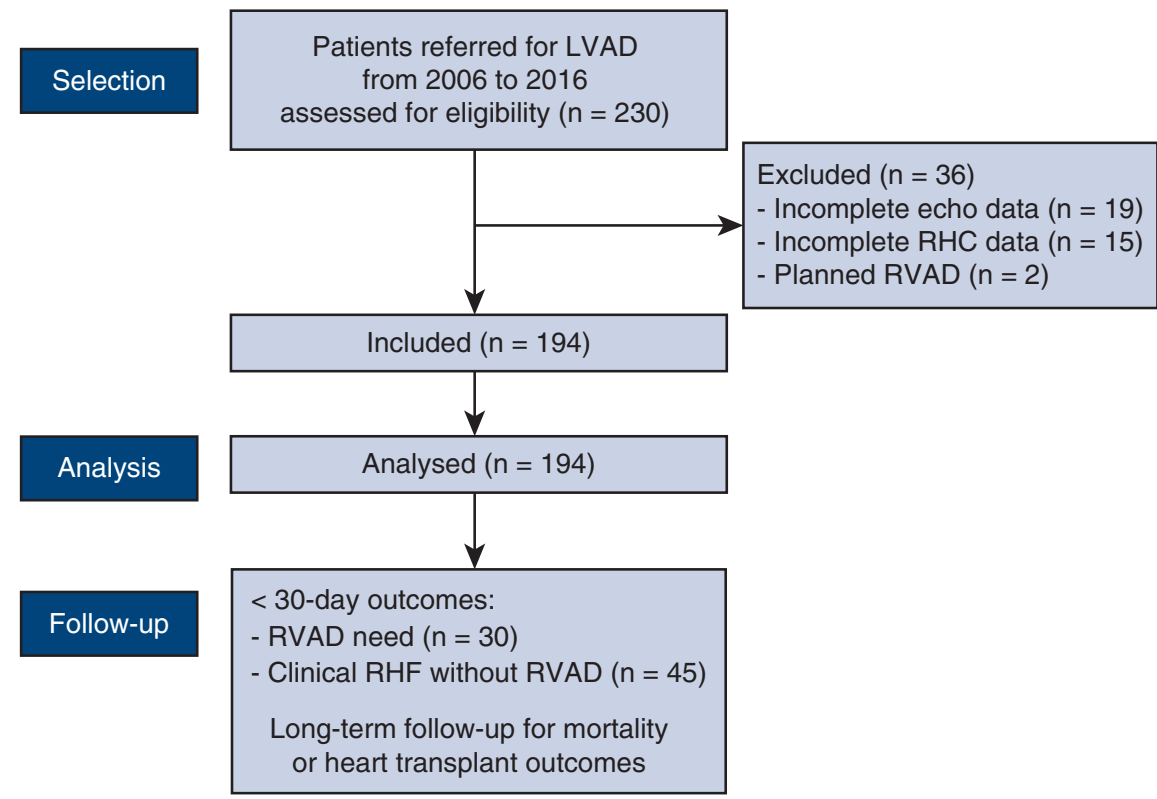

FIGURE 2. Flow chart of the study population. $L V A D$, Left ventricular assist device; $R H C$, right heart catheterization; $R V A D$, right ventricular assist device; $R H F$, right heart failure. 
TABLE 1. Preoperative characteristics of the study population $(\mathbf{n}=\mathbf{1 9 4})$

\begin{tabular}{|c|c|}
\hline Variable & Result \\
\hline Age (y) & $55.4 \pm 13.0$ \\
\hline Male sex & $150(77.3)$ \\
\hline Body mass index & $27.7 \pm 6.2$ \\
\hline Ischemic etiology & $63(32.5)$ \\
\hline Destination therapy & $72(37.1)$ \\
\hline Chronic kidney disease & $90(46.4)$ \\
\hline Prior cardiac surgery & $45(23.2)$ \\
\hline History of atrial fibrillation or flutter & $84(43.3)$ \\
\hline Heart rate (bpm) & $86.6 \pm 18.6$ \\
\hline Systolic blood pressure (mm Hg) & $101.4 \pm 12.7$ \\
\hline Mechanical ventilation & $14(7.2)$ \\
\hline Preoperative mechanical circulatory support* & $41(21.1)$ \\
\hline Inotropes $\dagger$ & $141(72.7)$ \\
\hline Vasopressors $\dagger$ & $32(16.5)$ \\
\hline \multicolumn{2}{|l|}{ INTERMACS profiles } \\
\hline 1 & $29(14.9)$ \\
\hline 2 & $65(33.5)$ \\
\hline 3 & $53(27.3)$ \\
\hline$\geq 4$ & $47(24.2)$ \\
\hline Hemoglobin (g/dL) & $11.5 \pm 2.9$ \\
\hline Creatinine level (mg/dL) & $1.6 \pm 0.8$ \\
\hline $\begin{array}{l}\text { MDRD estimated glomerular filtration rate } \\
\left(\mathrm{mL} / \mathrm{min} / 1.73 \mathrm{~m}^{2}\right)\end{array}$ & $56.1 \pm 23.4$ \\
\hline Blood urea nitrogen $(\mathrm{mg} / \mathrm{dL})$ & $29.5 \pm 16.6$ \\
\hline Aspartate aminotransferase (U/L) & $48.7 \pm 61.1$ \\
\hline Total bilirubin (mg/dL) & $1.4 \pm 1.3$ \\
\hline Index normalized ratio & $1.5 \pm 0.5$ \\
\hline \multicolumn{2}{|l|}{ Hemodynamic parameters } \\
\hline Mean right atrial pressure $(\mathrm{mm} \mathrm{Hg})$ & $12.1 \pm 7.1$ \\
\hline Systolic pulmonary arterial pressure $(\mathrm{mm} \mathrm{Hg})$ & $52.5 \pm 15.7$ \\
\hline Diastolic pulmonary arterial pressure $(\mathrm{mm} \mathrm{Hg})$ & $25.3 \pm 8.9$ \\
\hline Pulse pressure $(\mathrm{mm} \mathrm{Hg})$ & $27.2 \pm 10.2$ \\
\hline Mean pulmonary arterial pressure $(\mathrm{mm} \mathrm{Hg})$ & $35.3 \pm 10.8$ \\
\hline $\begin{array}{l}\text { Mean pulmonary arterial pressure:mean arterial } \\
\text { pressure }\end{array}$ & $0.47 \pm 0.15$ \\
\hline Pulmonary arterial wedge pressure $(\mathrm{mm} \mathrm{Hg})$ & $24.3 \pm 8.7$ \\
\hline Trans-pulmonary pressure gradient (mm Hg) & $11.3 \pm 6.4$ \\
\hline Cardiac index $\left(\mathrm{L} / \mathrm{min} / \mathrm{m}^{2}\right)$ & $1.9 \pm 0.7$ \\
\hline Stroke volume index $\left(\mathrm{mL} / \mathrm{m}^{2}\right)$ & $22.5 \pm 7.0$ \\
\hline Pulmonary vascular resistance (WU) & $3.5 \pm 2.3$ \\
\hline Pulmonary vascular resistance indexed $\left(\mathrm{WU} \cdot \mathrm{m}^{2}\right)$ & $6.5 \pm 4.5$ \\
\hline Pulmonary capacitance (mL/mm Hg) & $2.0 \pm 1.4$ \\
\hline Pulmonary capacitance indexed $\left(\mathrm{mL} / \mathrm{mm} \mathrm{Hg} / \mathrm{m}^{2}\right)$ & $1.0 \pm 0.7$ \\
\hline Pulmonary arterial elastance $(\mathrm{mm} \mathrm{Hg} / \mathrm{mL})$ & $1.2 \pm 0.6$ \\
\hline $\begin{array}{l}\text { Right atrial pressure:pulmonary arterial wedge } \\
\text { pressure }\end{array}$ & $0.50 \pm 0.23$ \\
\hline
\end{tabular}

(Continued)
TABLE 1. Continued

\begin{tabular}{lc}
\hline \multicolumn{1}{c}{ Variable } & Result \\
\hline Echocardiography & \\
LV ejection fraction $(\%)$ & $19.7 \pm 5.4$ \\
LV internal end-diastolic diameter $(\mathrm{mm})$ & $70.5 \pm 11.1$ \\
RV end-diastolic area index $\left(\mathrm{cm}^{2} / \mathrm{m}^{2}\right)$ & $15.9 \pm 4.0$ \\
RV end-systolic area index $\left(\mathrm{cm}^{2} / \mathrm{m}^{2}\right)$ & $12.3 \pm 3.6$ \\
Right atrial area index $\left(\mathrm{cm}^{2} / \mathrm{m}^{2}\right)$ & $11.4 \pm 3.7$ \\
Tricuspid annular plane systolic excursion $(\mathrm{mm})$ & $14.1 \pm 4.3$ \\
RV fractional area change $(\%)$ & $23.4 \pm 7.1$ \\
RV longitudinal strain $(\%)$ & $-14.1 \pm 3.5$ \\
Severe tricuspid regurgitation $(\%)$ & $40(20.6)$ \\
Load adaptability indices & \\
RV area change:RV end-systolic area & $0.33 \pm 0.13$ \\
Diastolic Dandel index $\ddagger$ & $30.07 \pm 11.27$ \\
Systolic Dandel index $\ddagger$ & $36.28 \pm 14.41$ \\
Tricuspid annular plane systolic excursion:RV & $0.29 \pm 0.10$ \\
$\quad$ systolic pressure $(\mathrm{mm} / \mathrm{mm} \mathrm{Hg}) \ddagger$ & \\
Systolic pulmonary arterial pressure:cardiac index & $30.88 \pm 14.51$ \\
$\quad$ (mm Hg $\cdot$ min $\left.\cdot \mathrm{m}^{2} / \mathrm{L}\right)$ & \\
Mean pulmonary arterial pressure:cardiac index & $20.91 \pm 10.26$ \\
$\quad$ (mm Hg min $\left.\cdot \mathrm{m}^{2} / \mathrm{L}\right)$ & \\
Pulse pressure:right atrial pressure & $3.30 \pm 2.96$ \\
Mean pulmonary arterial pressure:right atrial & $4.01 \pm 3.13$ \\
$\quad$ pressure & \\
\hline
\end{tabular}

Values are presented as mean \pm standard deviation or number (\%). INTERMACS, Interagency Registry for Mechanically Assisted Circulatory Support classification; $M D R D$, Modification of Diet in Renal Disease Study Equation; $L V$, left ventricular; $R V$, right ventricular. *Mechanical circulatory support included intra-aortic balloon pumps and miniaturized LV assist devices (Impella; Abiomed Inc, Danvers, Mass, and Tandem Heart; Cardiac Assist Inc, Pittsburgh, Pa). †Inotropes included milrinone, dobutamine, and dopamine. Vasopressors included norepinephrine, phenylephrine, and vasopressin. ‡The tricuspid regurgitation Doppler envelope was interpretable in $82 \%$ of patients, enabling determination of these indices.

$(7 \%)$ in whom the ratio was below the 0.54 threshold while having high RAP and PAWP. Figure 3, $C$, displays the complete correlation heatmap of echocardiographic load adaptability indices. The Dandel indices and RVESAI were strongly correlated, whereas lateral wall functional metrics (ie, RV free-wall longitudinal strain, TAPSE, and TAPSE:RVSP) were moderately correlated. The correlation heatmap of hemodynamic parameter indices (Figure 3,D) highlights the strong correlation between RAP and indices, including RAP (ie, PP:RAP, MPAP:RAP, and RAP:PAWP). Similarly, relative pressure MPAP:MAP, MPAP:cardiac index, and SPAP:cardiac index were strongly correlated, which is explained by the linear correlations between MPAP, SPAP, and pulse pressure, as illustrated in Figure 3, A.

The primary end point $(<30$ day unplanned RVAD) occurred in 30 patients $(15 \%)$, whereas 45 patients $(23.2 \%)$ presented with $<30$ days of clinical RHF without requiring RVAD implantation. Figure 4 displays the unadjusted comparison of Kaplan-Meier survival curves of patients without RHF, patients presenting with RHF 
Relation between SPAP, PP and MPAP

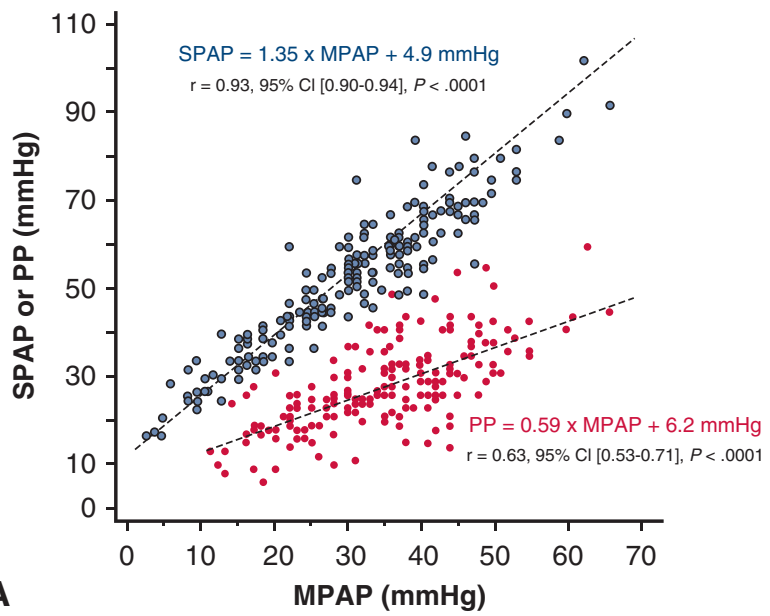

Correlation Heatmap of Echocardiographic Metrics

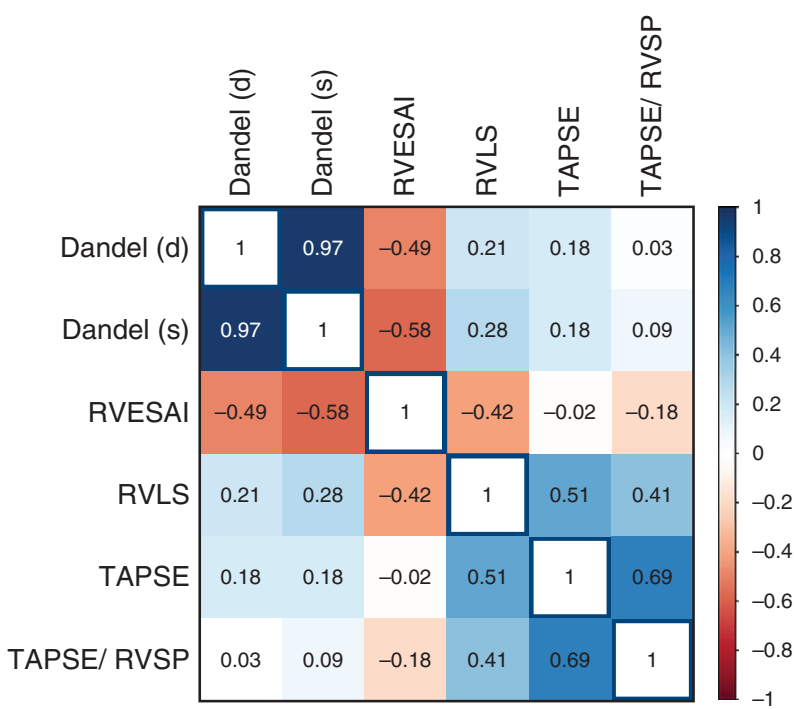

C

FIGURE 3. Correlation between right heart and load adaptation indices. A, Linear relationship between mean pulmonary arterial pressure (MPAP), systolic pulmonary arterial pressure $(S P A P)$, and pulse pressure $(P P)$. B, Venn diagram demonstrating the overlap between right atrial pressure $(R A P)$, pulmonary arterial wedge pressure $(P A W P)$, and the RAP to PAWP ratio. C, Correlation heatmap showing echocardiographic indices. D, Correlation heatmap showing hemodynamic parameter indices. Correlations are expressed as Pearson correlation coefficients $(r)$ and their $95 \%$ confidence interval $(95 \% \mathrm{CI})$ and $P$ value. $C I$, Cardiac index; RVESAI, right ventricular end-systolic area index on body surface area; RVLS, right ventricular free-wall longitudinal strain; TAPSE, tricuspid annular plane systolic excursion; $R V S P$, right ventricular systolic pressure; MAP, mean arterial pressure.

without requiring RVAD, and patients requiring RVAD. Transplant-free survival rates at 1 year were $91.3 \% \pm 2.8 \%$ in patients without RHF, $70.5 \% \pm 7.8 \%$ in patients with RHF who did not require RVAD implantation, and $39.0 \% \pm 9.6 \%$ in patients who required RVAD implantation $(P<.001)$. At 2 years, transplant-free survival rates were $88.4 \% \pm 3.4 \%, 64.1 \% \pm 9.4 \%$, and $26.0 \% \pm 1$ $2.4 \%$, respectively $(P<.001)$.

The comparative preoperative clinical, invasive, and echocardiographic characteristics of patients according to

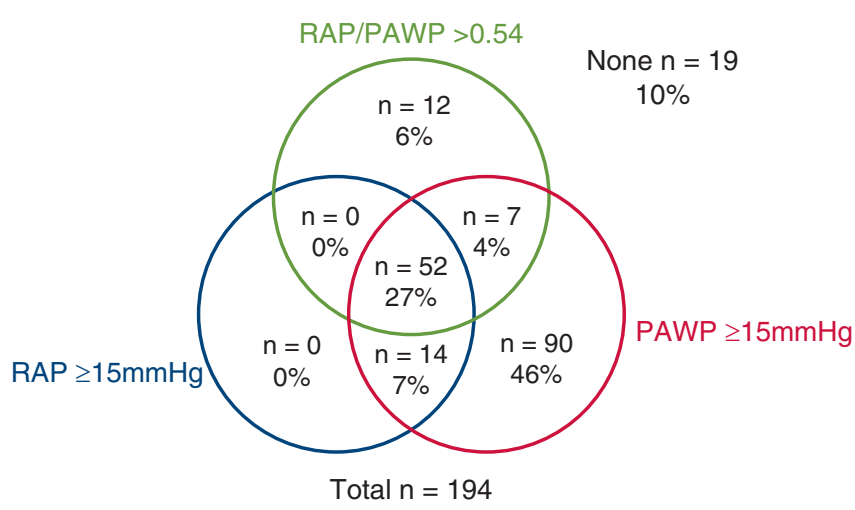

B

\section{Correlation Heatmap of Hemodynamics}

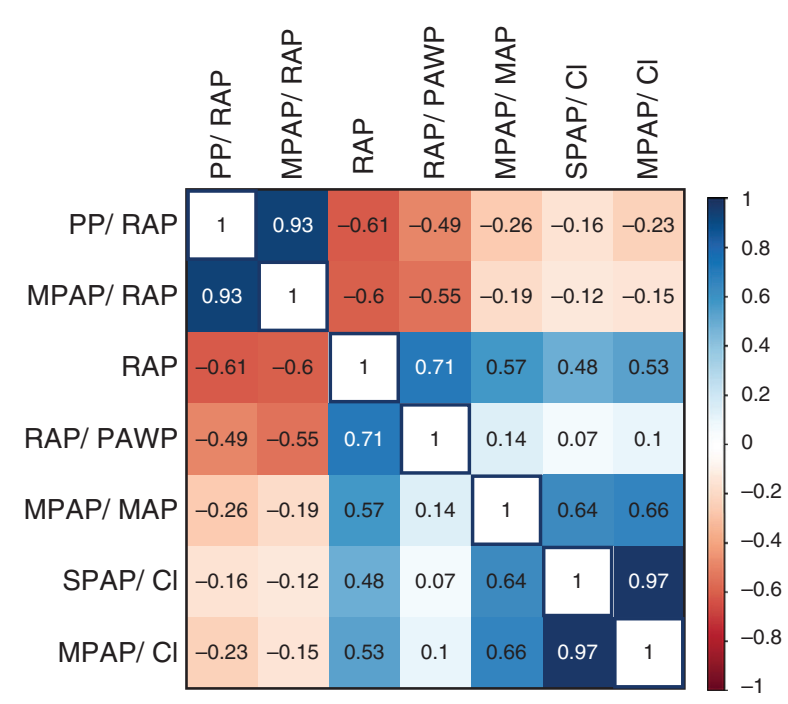

D

the need of RVAD or onset of clinical RHF are presented in Table E2. Among load adaptability metrics, only RV area change:RV end-systolic area and the Dandel indices significantly differed according to the groups using analysis of variance. The RV area change:RV end-systolic area was lower in patients with RVAD need $(0.28 \pm 0.11)$ or clinical RHF $(0.28 \pm 0.10)$ than in patients without RHF $(0.34 \pm 0.14)(P=.01)$. Both the diastolic and systolic Dandel indices were lower in patients with clinical RHF (24.62 \pm 7.53 and $28.99 \pm 8.99$, respectively) and in those 


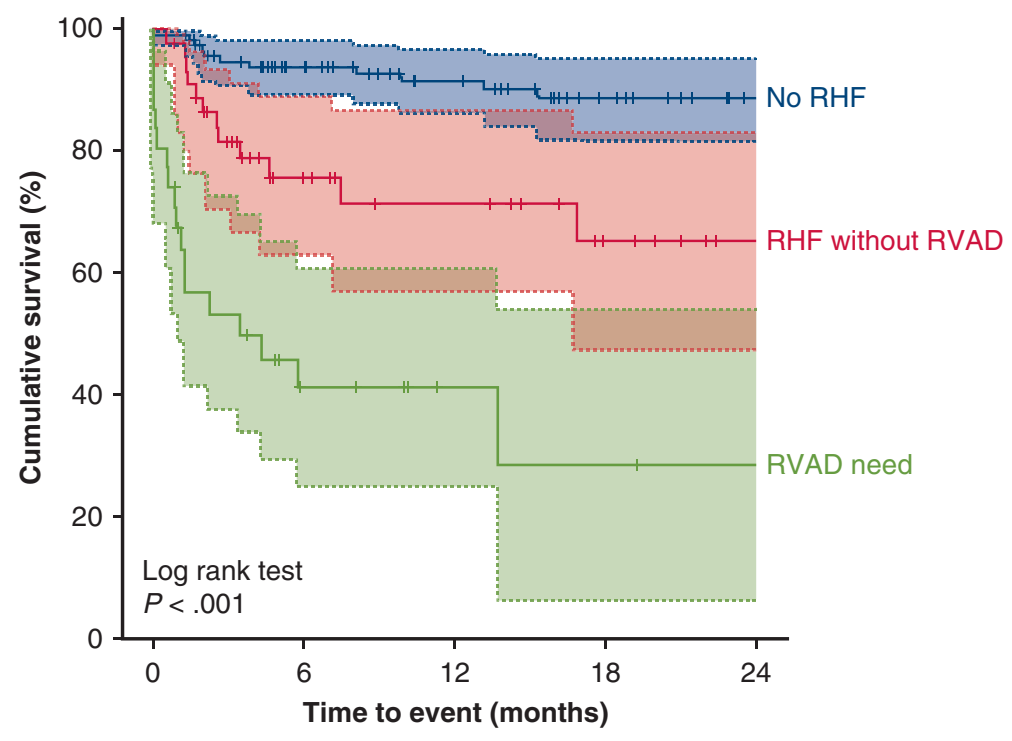

Number at risk

$\begin{array}{lccccc}\text { No RHF } & 119 & 89 & 69 & 52 & 44 \\ \text { RHF without RVAD } & 45 & 20 & 15 & 8 & 3 \\ \text { RVAD need } & 30 & 7 & 3 & 2 & 1\end{array}$

FIGURE 4. Two-year Kaplan-Meier heart cumulative survival curve of patients who underwent left ventricular assist device (LVAD) implantation according to the $<30$-day need of right ventricular assist device $(R V A D)$ implantation or onset of clinical right heart failure $(R H F)$. For the RVAD and RHF without RVAD groups, time 0 represents the date of event (ie, date of RVAD implantation for the RVDA group and date of RHF diagnosis for the RHF without RVAD group). For the no RHF group, time 0 was chosen from the median time between LVAD implantation and events from the 2 other groups (ie, 6.8 days after LVAD). Patients who underwent heart transplant were right censored at the time of transplant. Unadjusted comparisons between the three groups were performed using log-rank test.

requiring RVAD implantation $(27.27 \pm 8.41$ and $32.29 \pm 10.56$, respectively) than in those without RHF at 30 days ( $33.10 \pm 12.23$ and $40.40 \pm 15.67)$ (both $P$ values $<.001)$. RAP:PAWP was the only significant interventricular ratio differing between the groups. Among the 14 patients with low RAP:PAWP $(\leq 0.54)$ and high RAP $(\geq 15 \mathrm{~mm} \mathrm{Hg}), 6(43 \%)$ developed RHF after LVAD implantation, including 3 requiring RVAD implantation.

The univariable analyses of correlates of RVAD need (primary end point $[\mathrm{n}=194]$ ) are presented in Table 2 . Worst INTERMACS profiles, higher RAP, and RV enlargement (using RVESAI) were all significantly associated with RVAD need. None of MPAP, pulmonary vascular resistance, or capacitance were statistically associated with RVAD need (all $P$ values $>$.12). Among load adaptability metrics, TAPSE:RVSP, PP:RAP $<2.0$, and MPAP:RAP $<2.5$ were significantly associated with RVAD need, whereas RAP:PAWP was the only interventricular ratio associated with RVAD need. Overall, these indices had a similar area under the receiver operator characteristics curve than RAP (Figure 5, A). Figure 5, $B$, assesses the incremental value of these metrics to INTERMACS profiles, the Michigan score, and the EUROMACS score. The RV area change to RV end-systolic area ratio, PP:RAP $<2.0$, and RAP:PWAP provided significant incremental value to the INTERMACS profiles in a similar range to RAP or RVESAI. Only RAP provided significant incremental value to the Michigan score.

Stepwise multivariable models were built to predict RVAD need. To not overfit the model, 3 variables were included in addition to age and sex: INTERMACS profiles, RAP, and PP:RAP < 2.0. Using multivariable logistic regression, only worst INTERMACS profile (odd ratio [OR], 1.96; 95\% confidence interval (CI), 1.28-3.03; $P<.01)$ was retained in the model $\left(\chi^{2}, 10.79 ; P<.01\right)$. An alternative model, including RAP:PAWP instead of RAP (because these are correlated), provided the same result.

The univariable analyses of correlates of clinical RHF excluding RVAD need (secondary end point $[\mathrm{n}=164]$ ) are presented in Table E3. Worst INTERMACS profiles, RV enlargement (using RVESAI), and RV dysfunction (using RV free-wall longitudinal strain) were all significantly associated with clinical RHF (all $P$ values $<.01)$, whereas RAP was not $(P=.10)$. Among load adaptability metrics, RV area change:RV end-systolic area (adjusted OR, $1.58 ; 95 \% \mathrm{CI}, 1.07-2.45 ; P=.02$ ), the Dandel indices (diastolic adjusted OR, 3.38; 95\% CI, 1.77-626 and systolic adjusted OR, 3.62; 95\% CI, 2.077.08; both $P<.001)$ and PP:RAP $<2.0$ (OR, 2.32; 95\% 
TABLE 2. Univariate logistic regression analysis of correlates of right ventricular (RV) assist device (primary end point occurring in 30 out of 194 patients) after left ventricular (LV) assist device implantation

\begin{tabular}{|c|c|c|c|}
\hline Variable & $\frac{\text { Unadjusted (per unit change) }}{\text { OR }(95 \% \mathrm{CI})}$ & $\frac{\text { Adjusted (per SD change) }}{\text { OR }(95 \% \text { CI })^{*}}$ & $P$ value \\
\hline Age per unit or standard deviation decrease (y) & $1.02(0.99-1.05)$ & $1.30(0.88-1.96)$ & .15 \\
\hline INTERMACS profiles $\dagger$ & $1.96(1.28-3.03)$ & - & $<.01$ \\
\hline Right atrial pressure per unit or SD increase $(\mathrm{mm} \mathrm{Hg})$ & $1.07(1.02-1.13)$ & $1.62(1.15-2.38)$ & $<.01$ \\
\hline $\mathrm{RV}$ end-systolic area index per unit or SD increase $\left(\mathrm{cm}^{2} / \mathrm{m}^{2}\right)$ & $1.13(1.01-1.27)$ & $1.55(1.04-2.36)$ & $<.01$ \\
\hline RV longitudinal strain per unit or SD worsening (\%) & $1.12(0.97-1.28)$ & $1.49(0.90-2.38)$ & .11 \\
\hline \multicolumn{4}{|l|}{ Interventricular ratios } \\
\hline $\begin{array}{l}\text { Right atrial pressure:pulmonary arterial wedge pressure per } \\
\text { unit or SD increase }\end{array}$ & $7.42(1.42-38.83)$ & $1.59(1.08-2.32)$ & .02 \\
\hline $\begin{array}{l}\text { Mean pulmonary arterial pressure:mean arterial pressure per } \\
\text { unit or SD increase }\end{array}$ & $9.05(0.74-110.19)$ & $1.39(0.96-2.02)$ & .08 \\
\hline \multicolumn{4}{|l|}{ Ventriculoarterial coupling } \\
\hline $\mathrm{RV}$ area change:RV end-systolic area per unit or SD decrease & $20.00(0.65-1000.00)$ & $1.47(0.94-2.44)$ & .09 \\
\hline \multicolumn{4}{|l|}{ Physiologic indices } \\
\hline Diastolic Dandel’s index per unit or SD decrease $\ddagger$ & $1.03(0.98-1.09)$ & $1.41(0.80-2.56)$ & .18 \\
\hline Systolic Dandel's index per unit or SD decrease $\ddagger$ & $1.03(0.99-1.06)$ & $1.56(0.88-2.43)$ & .13 \\
\hline \multicolumn{4}{|l|}{ Ratio metrics } \\
\hline $\begin{array}{c}\text { Tricuspid annular plane systolic excursion:RV systolic } \\
\text { pressure per unit or SD decrease }(\mathrm{mm} / \mathrm{mm} \mathrm{Hg}) \ddagger\end{array}$ & $500.00(2.84-10,000.00)$ & $1.85(1.11-2.50)$ & .02 \\
\hline $\begin{array}{l}\text { Systolic pulmonary arterial pressure:cardiac index per unit or } \\
\text { SD increase }\left(\mathrm{mm} \mathrm{Hg} \cdot \min \cdot \mathrm{m}^{2} / \mathrm{L}\right)\end{array}$ & $1.01(0.99-1.04)$ & $1.16(0.86-1.77)$ & .40 \\
\hline $\begin{array}{l}\text { Mean pulmonary arterial pressure:cardiac index per unit or } \\
\text { SD increase }\left(\mathrm{mm} \mathrm{Hg} \cdot \min \cdot \mathrm{m}^{2} / \mathrm{L}\right)\end{array}$ & $1.02(0.98-1.05)$ & $1.23(0.81-1.65)$ & .41 \\
\hline Pulse pressure:right atrial pressure $<2.0$ & $2.56(1.16-5.56)$ & - & .02 \\
\hline Mean pulmonary arterial pressure:right atrial pressure $<2.5$ & $4.35(1.96-10.00)$ & - & $<.01$ \\
\hline
\end{tabular}

Bold indicates $P<.05$. SD, Standard deviation; OR, odds ratio; $C I$, confidence interval; INTERMACS, Interagency Registry for Mechanically Assisted Circulatory Support; $R V$, right ventricular. *ORs are presented as OR per SD for continuous variables and calculated as $\mathrm{OR}^{\mathrm{SD}}$. $\dagger$ Using INTERMACS classification $\geq 4$ as the reference group. $\ddagger$ Because the tricuspid regurgitation Doppler envelope was interpretable in $82 \%$ of patients, enabling determination of these indices. The logistic regression models were performed in $82 \%$ of the cohort

CI, 1.13-4.77; $P=.02$ ) were significantly associated with outcomes. None of the interventricular ratios were associated with RHF. The Dandel indices had the strongest area under the ROC curve but within the same range than RV end-sysolic area index (Figure 5,C). Similarly, both RV end-sysolic area index and the systolic Dandel index had similar incremental prognostic value to INTERMACS profiles, the Michigan score, and the EUROMACS score (Figure 5, D).

The univariable analyses of correlates of the secondary composite end point RHF or RVAD need $(n=194)$ are presented in Table E4. Worst INTERMACS profiles, higher RAP, RV enlargement (using RVESAI), and dysfunction (using free-wall longitudinal strain) were all significantly associated with outcomes (all $P$ values $<.01$ ). Among load adaptability metrics, RV area change:RV end-systolic area, the Dandel indices, PP:RAP $<2.0$ and MPAP:RAP $<2.5$ were all associated with outcomes (all $P$ values $<.01)$. RAP:PAWP was also associated with outcomes $(P=.02)$. The area under the receiver operator characteristics curve for the Dandel indices was similar to those of RVESAI or RV free-wall longitudinal strain (Figure E1,A). Both RVESAI and the systolic Dandel index had similar incremental prognostic value to INTERMACS profiles, the Michigan score, and the EUROMACS score (Figure E1, A).

\section{DISCUSSION}

This study is the first to critically compare invasive and noninvasive metrics of $\mathrm{RV}$ adaptation to load for prediction of RVAD need or RHF after LVAD implantation. Although load adaptability metrics or hemodynamic ratios show moderate prognostic value for RVAD need or clinical RHF post-LVAD implantation, they provide similar prognostic value to simple metrics such as RAP or RV end-systolic size, respectively (Video 1).

Several indices aiming to reflect RV adaptation to increased afterload have been published mainly in single-center LVAD studies. ${ }^{6,7,9,13}$ These indices can be divided into hemodynamic ratios and echocardiographic 


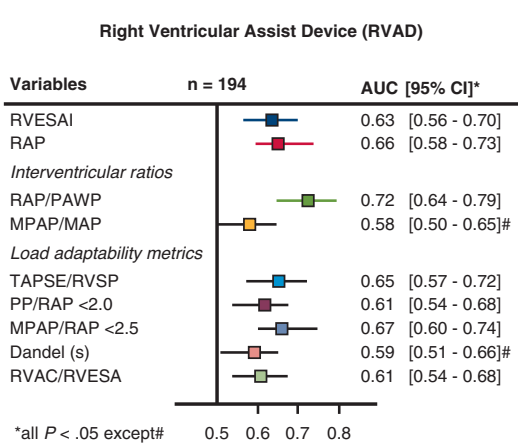

A

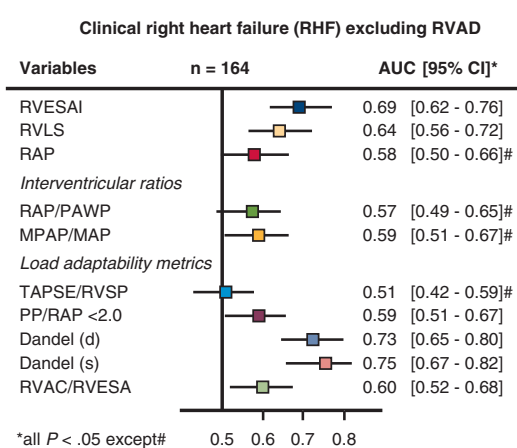

C

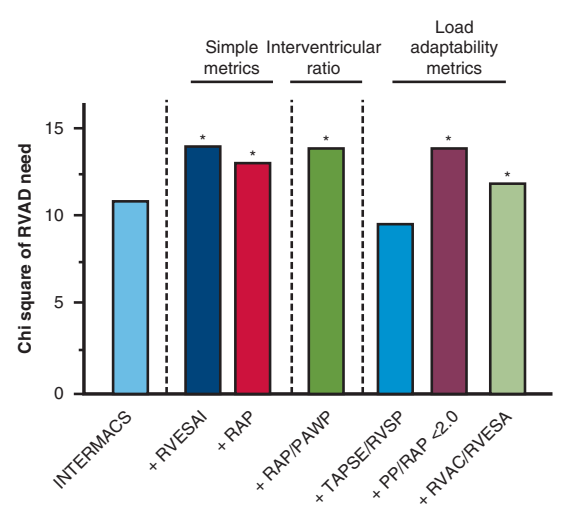

B
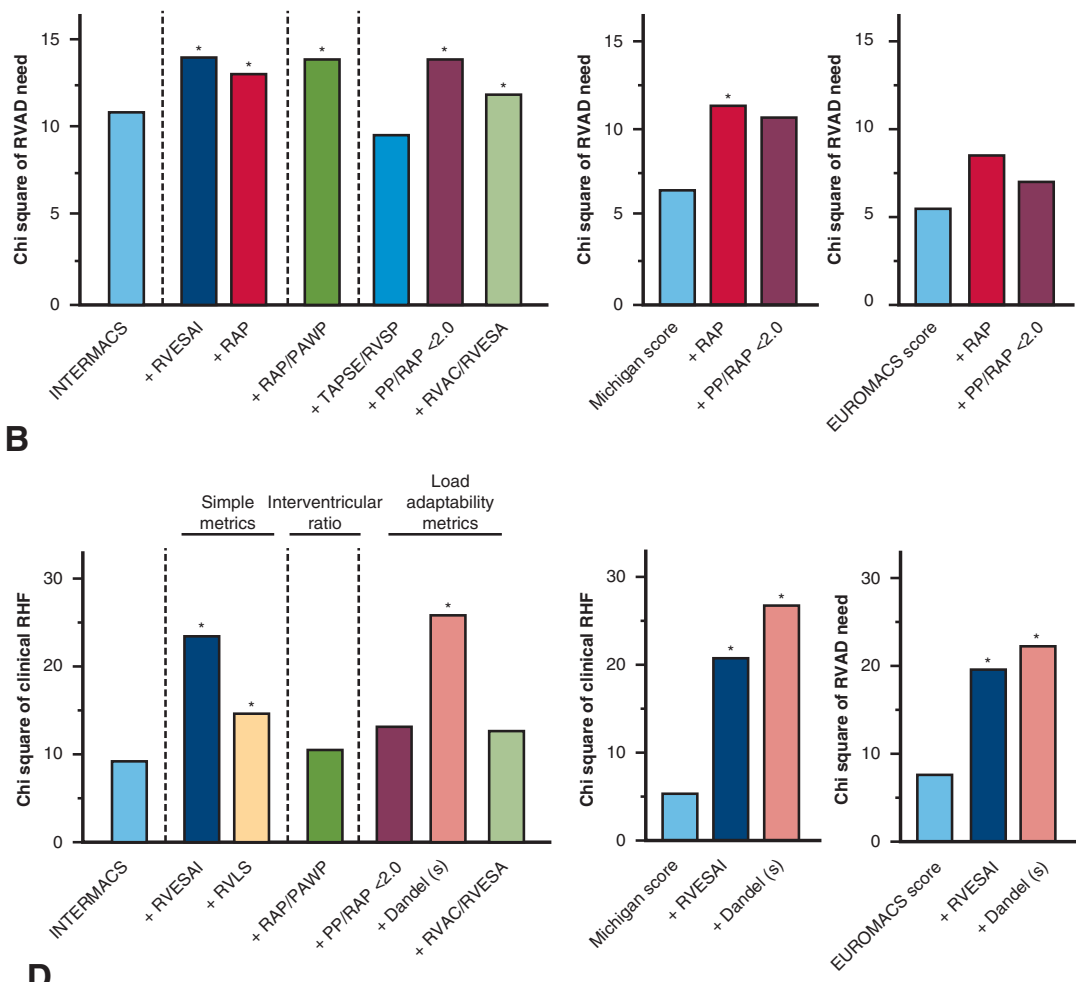

FIGURE 5. A, Area under the receiver-operating curve $(A U C)$ of right heart metrics for prediction of right ventricular atrial assist device $(R V A D)$ after left ventricular assist device $(L V A D)$ implantation. B, Incremental prognostic value of right heart metrics to Interagency Registry for Mechanically Assisted Circulatory Support (INTERMACS) profiles, the Michigan and European Registry for Patients with Mechanical Circulatory Support (EUROMACS) scores for RVAD need. C, AUC of right heart metrics for prediction of clinical right heart failure (RHF) without RVAD after LVAD implantation. D, Incremental prognostic value of right heart metrics to INTERMACS profiles, the Michigan and European EUROMACS scores for RHF. RVESAI, RV end-systolic area index; $R A P$, right atrial pressure; $P A W P$, pulmonary artery wedge pressure; $M P A P$, mean pulmonary arterial pressure; $M A P$, mean systemic arterial pressure; $T A S P E$, tricuspid annular systolic plane excursion; $R V S P, \mathrm{RV}$ systolic pressure; $R V E S A, \mathrm{RV}$ end-systolic area; $P P$, pulse pressure; $R V A C$, RV area change; $R V L S$, RV free-wall longitudinal strain. All $P$ values of each model were $<.05$ except when indicated by $\#$. $* P<.05$ for comparison with the INTERMACS, Michigan, or EUROMACS scores.

load adaptation metrics. Among hemodynamic ratios, the pulsatility index (PP:RAP), MPAP:RAP, and RAP:PAWP were strongly associated with RVAD need post-LVAD, consistent with previous publications. ${ }^{9,13}$ We confirmed in our cohort the physiologic linear relation between MPAP, $\mathrm{PP}$, and SPAP, which is a specific feature of pulmonary circulation. This results in the collinearity between hemodynamic ratios and explains in part their similar prognostic value. Our Venn diagram additionally illustrates the strong mathematic correlation between RAP:PAWP and RAP, contributing to a similar prognostic value. This was suggested in 2 previous large studies exploring the prognostic value of RAP:PAWP but not discussed. ${ }^{8,9}$ In 151 patients undergoing continuous-flow LVAD implantation, the OR $(95 \% \mathrm{CI})$ of the central venous pressure:PAWP for early RHF was 1.76 (1.24-2.52) similar to the OR $(95 \% \mathrm{CI})$ of central venous pressure 1.74 (1.22-2.47) (both $P$ values $<.01){ }^{8}$ Similarly, in the large EUROMACS derivation cohort, the OR of RAP:PAWP $>0.54$ (2.08; 95\% CI, 1.38-3.11; $P<.0001)$ overlapped with the OR of RAP $(1.73,95 \% \mathrm{CI}$, 1.28-2.34; $P=.001) .{ }^{9}$ The advantage of ratios such as RAP:PAWP is to identify patients with disproportional atrial pressures (ie, low RAP but higher than PAWP because of hypovolemia). In contrast, they expose to misclassification patients with low ratio because of higher PAWP than RAP in low-risk class. In our cohort, $43 \%$ of the 14 patients with low ratio and high RAP developed RVAD need or clinical RHF post-LVAD implantation.

The other originality of our study is to distinguish the different concepts behind the load adaptability term in 194 patients referred for continuous-flow LVAD implantation (Figure 1). The first concept (ventriculoarterial coupling) is represented by the ventricular to arterial elastance ratio using pressure-volume loop analysis. ${ }^{11}$ The stroke volume to end-systolic volume ratio have been 


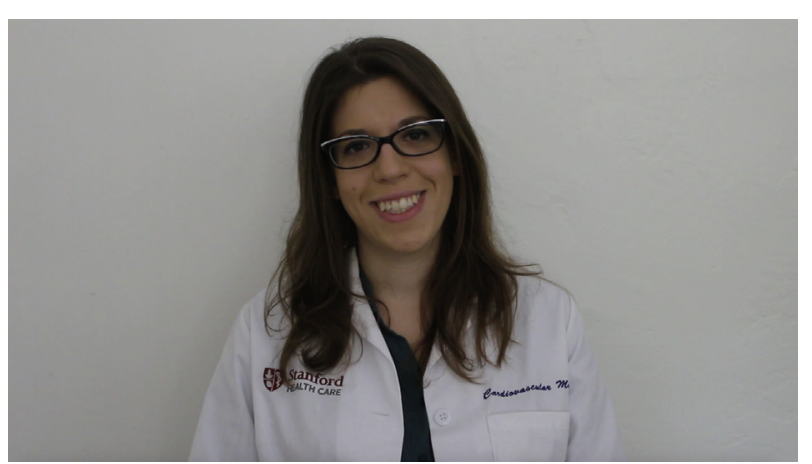

VIDEO 1. First author Dr Myriam Amsallem, MD, MS (from Stanford University Department of Cardiovascular Medicine) discussing the importance of early right heart failure after left ventricular assist device implantation and the results of this study. Video available at: https://www.jtcvs. org/article/S0022-5223(18)32490-5/fulltext.

proposed as a surrogate, neglecting the volume at pressure 0 , which can be large in patients with dilated RV such as in patients referred for LVAD as illustrated in our cohort. ${ }^{12}$ Using 2-dimensional echocardiography, we approximated this ratio by the RV area change:RV end-systolic area, showing moderate but significant association with outcomes. The second concept of physiologic indices is represented by Dandel's indices, relating the pressure gradient to the average transverse size of the RV. ${ }^{6}$ Although both the original Dandel diastolic index and our modified systolic index are validated in our cohort of continuous-flow LVAD and emerge as the strongest load adaptability predictors of clinical RHF not requiring RVAD implantation, these indices only provide a prognostic value similar to RVESAI. The strong correlation between the Dandel indices and RVESAI may explain why they provide similar level of prediction. Moreover, the Dandel indices require the presence of an interpretable tricuspid regurgitation signal. ${ }^{16}$ The last category regroups all combined metrics of function and load, regardless of their physiologic relationship. The ratio of TAPSE (reflecting longitudinal RV fiber shortening) and RV systolic pressure (ie, force generated by the RV) has been previously shown to be prognostic in 247 patients with heart failure reduced ejection fraction and 46 patients with heart failure preserved ejection fraction. ${ }^{7}$ Primarily demonstrated to predict survival in a less severe and more heterogeneous cohort of patients with heart failure, ${ }^{7}$ this index was moderately validated in our cohort for prediction of RVAD need post-LVAD implantation. Two main limitations emerges for this index: the use of TAPSE as a metric of RV function, which can be altered in patients with previous history of pericardial opening (about one-quarter of the cohort), ${ }^{21}$ and the highly dependence to a good quality of the tricuspid regurgitation Doppler envelope, ${ }^{16}$ limiting the use of this index in $80 \%$ of patients.

Our results suggest that hemodynamic indices (such as RAP, RAP:PAWP, or PP:RAP) better reflect the risk of
RVAD implantation post-LVAD than the RV end-systolic remodeling indices (such as RVESAI, RV area change: $\mathrm{RV}$ end-systolic area, or the systolic Dandel index) that better reflect RV dysfunction not requiring RVAD implantation. Overall, the main clinical implication of our study integrating both invasive and noninvasive assessment of the right heart is the simplification of prognostic markers of RVAD need or RHF postcontinuous-flow LVAD implantation, fitting in the current simple is better trend in the field of cardiovascular imaging. ${ }^{22}$ Although they are strong prognostic markers of RVAD need, hemodynamic ratios (such as RAP:PAWP) expose to the risk of misclassifying patients with both high values. Considering the technical challenge and variability in invasively determining PAWP, our results combined with previous studies suggest that RAP or central venous pressure provide similar prognostic value to RAP:PAWP. Similarly, identifying and measuring the tricuspid regurgitation envelope using echocardiography can be challenging in patients referred for LVAD who frequently have implantable cardioverter defibrillator and/ or cardiac resynchronization therapy devices, thus limiting the feasibility of Dandel indices. RV end-systolic area represents a simple metric, if measured carefully on RV focused apical 4-chamber view avoiding foreshortening. ${ }^{23}$ The importance of end-systolic remodeling, first described by Carabello and Spann in $1984,{ }^{24}$ highlighting end-systolic dimensions and stress-corrected end-systolic dimensions as the best predictors of postoperative recovery in valvular heart disease. Since then, RV end-systolic remodeling metrics (ie, area, volume using 3-dimensional echocardiography or cardiac magnetic resonance, or RV remodeling index defined as the RV lateral wall length divided by the septal height) have shown to be strong prognostic markers in patients with pulmonary hypertension. ${ }^{10,25-27}$ Physiologically, end-systolic dimension metrics integrate RV remodeling to increased afterload and RV dysfunction.

The first limitation of our study is inherent to its singlecenter design. However, this cohort primarily intends to act as a validation cohort of previous derivation cohorts describing load adaptability metrics. The second limitation may arise from the time delay between echocardiography and right heart catheterization, precluding more physiologic assessment of RV function or remodeling according to load, and limiting direct comparison between invasive and noninvasive load adaptability metrics. However, this delay reflects clinical practice in patients referred for LVAD implantation, in which these exams are often not simultaneous and usually not repeated before the surgery in case of clinical stability. In addition, no metric combining invasive and echocardiographic indices was used in this study. The third limitation may come from the large number of candidate variables evaluated in this study exposing to the risk of spurious association. However, these candidates 
were identified from previously published variables and the primarily aim of this study was to externally validate them. The overall number of events precluded high statistical power for multivariable modeling, but allowed exploration of the incremental value of these variables on top of validated risk scores. Finally, this study has not prospectively collected data on perioperative complications and aggravating factors that influence the RV (such as the number of blood transfusions).

\section{CONCLUSIONS}

Although our study confirms that RAP:PAWP is a good prognostic index of load adaptability associated with the risk of RVAD implantation post-LVAD, our findings do not validate its incremental value on validated scores beyond simple metrics such as RAP. Similarly, the Dandel indices are associated with the risk of RHF without RVAD need post-LVAD, but in a similar extent to RVESAI.

\section{Conflict of Interest Statement}

Dr Teuteberg has received financial support from Medtronic, Abiomed, and CareDx (speaker and member of advisory boards) and from Abbott (member of the HeartMate3 Clinical Events Committee). Dr Banerjee has received financial research support from Abbott and Medtronic. All other authors have nothing to disclose with regard to commercial support.

The authors would like to thank Yael Vanessa Cywiak (C.Y.V. Productions) for her assistance with the production of the video included in this article.

\section{References}

1. Patlolla B, Beygui R, Haddad F. Right-ventricular failure following left ventricle assist device implantation. Curr Opin Cardiol. 2013;28:223-33.

2. Kiernan MS, French AL, DeNofrio D, Parmar YJ, Pham DT, Kapur NK, et al. Preoperative three-dimensional echocardiography to assess risk of right ventricular failure after left ventricular assist device surgery. J Card Fail. 2015;21: 189-97.

3. LaRue SJ, Raymer DS, Pierce BR, Nassif ME, Sparrow CT, Vader JM. Clinical outcomes associated with INTERMACS-defined right heart failure after left ventricular assist device implantation. J Heart Lung Transplant. 2017;36:475-7.

4. Bartfay S-E, Dellgren G, Lidén H, Holmberg M, Gäbel J, Redfors B, et al. Are biventricular assist devices underused as a bridge to heart transplantation in patients with a high risk of postimplant right ventricular failure? J Thorac Cardiovasc Surg. 2017;153:360-7.

5. Lampert BC, Teuteberg JJ. Right ventricular failure after left ventricular assist devices. J Heart Lung Transplant. 2015;34:1123-30.

6. Dandel M, Potapov E, Krabatsch T, Stepanenko A, Löw A, Vierecke J, et al. Load dependency of right ventricular performance is a major factor to be considered in decision making before ventricular assist device implantation. Circulation. 2013; 128:14-23.

7. Guazzi M, Bandera F, Pelissero G, Castelvecchio S, Menicanti L, Ghio S, et al. Tricuspid annular plane systolic excursion and pulmonary arterial systolic pressure relationship in heart failure: an index of right ventricular contractile function and prognosis. Am J Physiol Heart Circ Physiol. 2013;305:1373-81.

8. Grandin EW, Zamani P, Mazurek JA, Troutman GS, Birati EY, Vorovich E, et al. Right ventricular response to pulsatile load is associated with early right heart failure and mortality after left ventricular assist device. J Heart Lung Transplant. 2017:36:97-105.
9. Soliman OI, Akin S, Muslem R, Boersma E, Manintveld OC, Krabatsch T, et al. Derivation and validation of a novel right-sided heart failure model after implantation of continuous flow left ventricular assist devices: the EUROMACS (European registry for patients with mechanical circulatory support) right-sided heart failure risk score. Circulation. 2018;137:891-906.

10. Amsallem M, Boulate D, Aymami M, Guihaire J, Selej M, Huo J, et al. Load adaptability in patients with pulmonary arterial hypertension. Am J Cardiol. 2017; 120:874-82.

11. Boulate D, Mercier O, Guihaire J, Fadel E, Naeije R, Haddad F, et al. Pulmonary circulatory - right ventricular uncoupling: new insights into pulmonary hypertension pathophysiology. In: Pulmonary Hypertension: Basic Science to Clinical Medicine. Geneva: Springer International Publishing; 2016:241-56.

12. Trip P, Kind T, Veerdonk MC van de, Marcus JT, Man FS de, Westerhof N, et al Accurate assessment of load-independent right ventricular systolic function in patients with pulmonary hypertension. J Heart Lung Transplant. 2013;32:50-5.

13. Kang G, Ha R, Banerjee D. Pulmonary artery pulsatility index predicts right ventricular failure after left ventricular assist device implantation. J Heart Lung Transplant. 2016;35:67-73.

14. Matthews JC, Koelling TM, Pagani FD, Aaronson KD. The right ventricular failure risk score a pre-operative tool for assessing the risk of right ventricular failure in left ventricular assist device candidates. J Am Coll Cardiol. 2008;51: 2163-72.

15. Lang RM, Badano LP, Mor-Avi V, Afilalo J, Armstrong A, Ernande L, et al. Recommendations for cardiac chamber quantification by echocardiography in adults: an update from the American Society of Echocardiography and the European Association of Cardiovascular Imaging. J Am Soc Echocardiogr. 2015;28:1-39.e14.

16. Amsallem M, Sternbach JM, Adigopula S, Kobayashi Y, Vu TA, Zamanian R, et al. Addressing the controversy of estimating pulmonary arterial pressure by echocardiography. J Am Soc Echocardiogr. 2016;29:93-102.

17. Robitaille A, Denault AY, Couture P, Bélisle S, Fortier A, Guertin M-C, et al Importance of relative pulmonary hypertension in cardiac surgery: the mean systemic-to-pulmonary artery pressure ratio. J Cardiothorac Vasc Anesth. 2006;20:331-9.

18. Mahapatra S, Nishimura RA, Sorajja P, Cha S, McGoon MD. Relationship of pulmonary arterial capacitance and mortality in idiopathic pulmonary arterial hypertension. J Am Coll Cardiol. 2006;47:799-803.

19. Chemla D, Antony I, Lecarpentier Y, Nitenberg A. Contribution of systemic vascular resistance and total arterial compliance to effective arterial elastance in humans. Am J Physiol Heart Circ Physiol. 2003;285:614-20.

20. Saydain G, Awan A, Manickam P, Kleinow P, Badr S. Pulmonary hypertension an independent risk factor for death in intensive care unit: correlation of hemodynamic factors with mortality. Clin Med Insights Circ Respir Pulm Med. 2015;9:27-33.

21. Tamborini G, Muratori M, Brusoni D, Celeste F, Maffessanti F, Caiani EG et al. Is right ventricular systolic function reduced after cardiac surgery? A two- and three-dimensional echocardiographic study. Eur J Echocardiogr. 2009; 10:630-4.

22. Oxborough D, Lord R. predicting mortality in pulmonary arterial hypertension: can it really be that simple? JACC Cardiovasc Imaging. 2015;8:639-41.

23. Amsallem M, Lu H, Tang X, Do Couto Francisco N, Kobayashi Y, Moneghetti K, et al. Optimizing right ventricular focused four-chamber views using threedimensional imaging: a comparative magnetic resonance based study. Int J Cardiovasc Imaging. 2018;34:1409-17.

24. Carabello BA, Spann JF. The uses and limitations of end-systolic indexes of left ventricular function. Circulation. 1984;69:1058-64.

25. Amsallem M, Sweatt AJ, Aymami MC, Kuznetsova T, Selej M, Lu H, et al. Right heart end-systolic remodeling index strongly predicts outcomes in pulmonary arterial hypertension: comparison with validated models. Circ Cardiovasc Imaging. 2017;10.

26. Veerdonk MC van de, Kind T, Marcus JT, Mauritz G-J, Heymans MW Bogaard H-J, et al. Progressive right ventricular dysfunction in patients with pulmonary arterial hypertension responding to therapy. J Am Coll Cardiol. 2011;58: 2511-9.

27. Ryo K, Goda A, Onishi T, Delgado-Montero A, Tayal B, Champion HC, et al. Characterization of right ventricular remodeling in pulmonary hypertension associated with patient outcomes by 3-dimensional wall motion tracking echocardiography. Circ Cardiovasc Imaging. 2015;8:e003176.

Key Words: right heart failure, left ventricular assist device, load-adaptation coupling, outcomes 

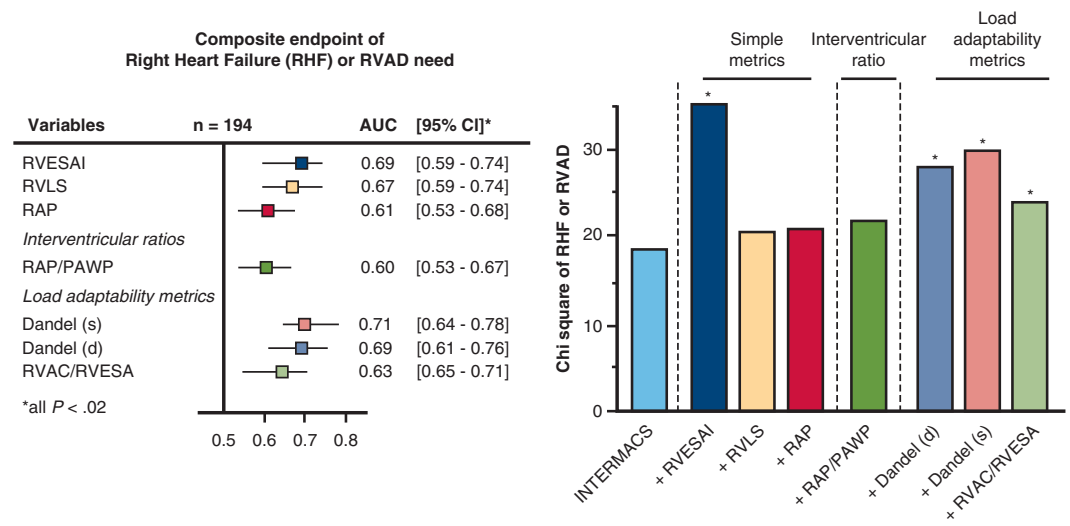

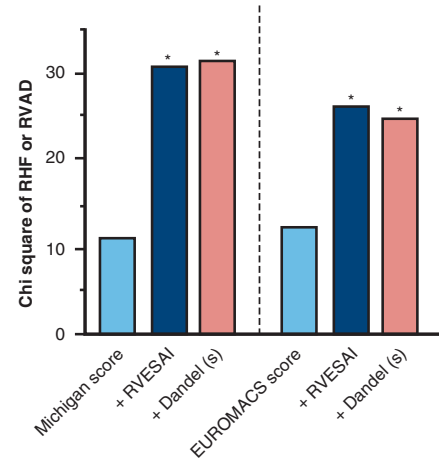

FIGURE E1. Left panel, Area under the receiver-operating curve (AUC) of right heart metrics for prediction of the composite secondary end point of right ventricular assist device $(R V A D)$ or clinical right heart failure $(R H F)$ after left ventricular assist device (LVAD) implantation. Right panel, Incremental prognostic value of right heart metrics to Interagency Registry for Mechanically Assisted Circulatory Support (INTERMACS) profiles, the Michigan scores, and European Registry for Patients with Mechanical Circulatory Support (EUROMACS) scores. RVESAI, RV end-systolic area index; RVLS, RV free-wall longitudinal strain; $C I$, cardiac index; $R A P$, right atrial pressure; $P A W P$, pulmonary artery wedge pressure; $R V S P, \mathrm{RV}$ systolic pressure; $R V A C, \mathrm{RV}$ area change; $R V E S A, \mathrm{RV}$ end-systolic area. All $P$ values of each model were $<.02 .{ }^{*} P<.05$ for comparison with the INTERMACS, Michigan, or EUROMACS scores.

TABLE E1. Risk scores predicting right heart failure after left ventricular assist device implantation

\begin{tabular}{ll}
\hline \multicolumn{1}{c}{ Risk score } & Variables included in the score \\
\hline Michigan score $^{14}$ & Vasopressor requirement \\
& Aspartate aminotransferase $\geq 80 \mathrm{IU} / \mathrm{L}$ \\
& Total bilirubin $\geq 2 \mathrm{mg} / \mathrm{dL}$ \\
& Creatinine $\geq 2.3 \mathrm{mg} / \mathrm{dL}$ \\
European Registry for & Interagency Registry for Mechanically \\
Patients with & Assisted Circulatory Support \\
Mechanical Circulatory & classes $1-3$ \\
Support & Use of multiple inotropes \\
& Severe right ventricular dysfunction \\
& Ratio of right atrial:pulmonary arterial \\
& wedge pressure $>0.54$ \\
& Hemoglobin $\leq 10 \mathrm{~g} / \mathrm{dL}$ \\
\hline
\end{tabular}


TABLE E2. Preoperative characteristics of the study population according to onset of right heart failure (RHF) or need for right ventricular assist device (RVAD) implantation

\begin{tabular}{|c|c|c|c|c|}
\hline Variable & $\begin{array}{l}\text { No RHF } \\
(n=119)\end{array}$ & $\begin{array}{l}\text { RHF without RVAD } \\
(\mathbf{n}=45)\end{array}$ & $\begin{array}{l}\text { Need for RVAD } \\
\qquad(\mathbf{n}=\mathbf{3 0})\end{array}$ & $P$ value* \\
\hline Age (y) & $57.1 \pm 11.9$ & $53.0 \pm 14.3$ & $52.2 \pm 14.7$ & .07 \\
\hline Male sex & $85(71.4)$ & $39(86.7)$ & $26(86.7)$ & .05 \\
\hline Body mass index & $28.0 \pm 6.2$ & $26.9 \pm 4.8$ & $27.2 \pm 7.9$ & .55 \\
\hline Ischemic etiology & $43(36.1)$ & $11(24.4)$ & $9(30.0)$ & .34 \\
\hline Destination Therapy & $53(44.5)$ & $9(20.0)$ & $10(33.3)$ & .01 \\
\hline Chronic kidney disease & $57(47.9)$ & $25(55.6)$ & $8(26.7)$ & .04 \\
\hline Prior cardiac surgery & $34(28.6)$ & $4(8.9)$ & $7(23.3)$ & .03 \\
\hline History of atrial fibrillation or flutter & $48(40.3)$ & $23(51.1)$ & $13(43.3)$ & .46 \\
\hline Heart rate (bpm) & $87.1 \pm 15.9$ & $93.7 \pm 19.2$ & $87.7 \pm 13.6$ & .07 \\
\hline Systolic blood pressure (mm Hg) & $103.1 \pm 12.9$ & $98.2 \pm 14.7$ & $99.9 \pm 16.5$ & .11 \\
\hline Mechanical ventilation & $5(4.2)$ & $4(8.9)$ & $5(16.7)$ & .05 \\
\hline Preoperative mechanical circulatory support & $14(11.8)$ & $14(31.1)$ & $13(43.3)$ & $<.001$ \\
\hline Inotropes & $78(65.5)$ & $37(82.2)$ & $26(86.7)$ & .02 \\
\hline Vasopressors & $14(11.8)$ & $9(20.0)$ & $9(30.0)$ & .04 \\
\hline $\begin{array}{l}\text { INTERMACS profiles } \\
\qquad \begin{array}{l}1 \\
2 \\
3 \\
\geq 4\end{array}\end{array}$ & $\begin{array}{c}9(7.6) \\
34(28.6) \\
41(34.5) \\
35(29.4)\end{array}$ & $\begin{array}{c}8(17.8) \\
23(51.1) \\
6(13.3) \\
8(17.8)\end{array}$ & $\begin{array}{c}12(40.0) \\
8(26.7) \\
6(20.0) \\
4(13.3)\end{array}$ & $<.001$ \\
\hline Hemoglobin (g/dL) & $11.7 \pm 2.5$ & $10.9 \pm 1.7$ & $11.8 \pm 4.9$ & .26 \\
\hline Creatinine level (mg/dL) & $1.48 \pm 0.58$ & $1.77 \pm 1.37$ & $1.53 \pm 0.52$ & .13 \\
\hline $\begin{array}{l}\text { MDRD estimated glomerular filtration rate } \\
\left(\mathrm{mL} / \mathrm{min} / 1.73 \mathrm{~m}^{2}\right)\end{array}$ & $56.9 \pm 23.8$ & $54.6 \pm 25.0$ & $55.5 \pm 19.5$ & .84 \\
\hline Blood urea nitrogen $(\mathrm{mg} / \mathrm{dL})$ & $27.2 \pm 15.7$ & $33.0 \pm 16.7$ & $33.7 \pm 18.6$ & .04 \\
\hline Aspartate aminotransferase (U/L) & $46.1 \pm 61.1$ & $45.8 \pm 55.5$ & $63.0 \pm 68.8$ & .38 \\
\hline Total bilirubin (mg/dL) & $1.10 \pm 0.69$ & $1.07 \pm 1.48$ & $2.22 \pm 2.24$ & $<.001$ \\
\hline \multicolumn{5}{|l|}{ Hemodynamic parameters } \\
\hline Mean right atrial pressure (mm $\mathrm{Hg})$ & $11.0 \pm 6.8$ & $13.1 \pm 7.6$ & $15.3 \pm 6.1$ & $<.001$ \\
\hline Systolic pulmonary arterial pressure (mm Hg) & $51.6 \pm 16.9$ & $53.5 \pm 13.0$ & $54.7 \pm 14.4$ & .56 \\
\hline Diastolic pulmonary arterial pressure $(\mathrm{mm} \mathrm{Hg})$ & $24.6 \pm 9.7$ & $26.2 \pm 7.3$ & $27.1 \pm 7.2$ & .31 \\
\hline Pulse pressure $(\mathrm{mm} \mathrm{Hg})$ & $27.0 \pm 10.2$ & $27.4 \pm 9.7$ & $28.0 \pm 11.5$ & .90 \\
\hline Mean pulmonary arterial pressure $(\mathrm{mm} \mathrm{Hg})$ & $34.6 \pm 11.8$ & $36.0 \pm 8.7$ & $37.1 \pm 9.1$ & .48 \\
\hline $\begin{array}{l}\text { Mean pulmonary arterial pressure:mean arterial } \\
\text { pressure }\end{array}$ & $0.44 \pm 0.15$ & $0.49 \pm 0.15$ & $0.51 \pm 0.15$ & .05 \\
\hline Cardiac index $\left(\mathrm{L} / \mathrm{min} / \mathrm{m}^{2}\right)$ & $1.91 \pm 0.75$ & $1.94 \pm 0.60$ & $1.86 \pm 0.62$ & .89 \\
\hline Pulmonary vascular resistance (WU) & $3.48 \pm 2.34$ & $3.35 \pm 2.18$ & $3.59 \pm 2.57$ & .90 \\
\hline Pulmonary vascular resistance indexed $\left(\mathrm{WU} \cdot \mathrm{m}^{2}\right)$ & $6.71 \pm 4.83$ & $6.52 \pm 3.98$ & $6.17 \pm 4.21$ & .84 \\
\hline $\begin{array}{l}\text { Right atrial pressure:pulmonary arterial wedge } \\
\text { pressure }\end{array}$ & $0.47 \pm 0.21$ & $0.52 \pm 0.24$ & $0.59 \pm 0.23$ & .02 \\
\hline \multicolumn{5}{|l|}{ Echocardiography } \\
\hline RV end-systolic area index $\left(\mathrm{cm}^{2} / \mathrm{m}^{2}\right)$ & $11.3 \pm 3.4$ & $13.9 \pm 3.4$ & $13.6 \pm 3.4$ & $<.001$ \\
\hline Right atrial area index $\left(\mathrm{cm}^{2} / \mathrm{m}^{2}\right)$ & $10.3 \pm 2.9$ & $13.1 \pm 4.0$ & $13.4 \pm 4.0$ & $<.001$ \\
\hline RV longitudinal strain (\%) & $-14.8 \pm 3.8$ & $-12.9 \pm 3.3$ & $-12.9 \pm 1.8$ & $<.001$ \\
\hline RV fractional area change $(\%)$ & $24.6 \pm 7.5$ & $21.6 \pm 5.9$ & $21.3 \pm 6.0$ & .01 \\
\hline Tricuspid annular plane systolic excursion (mm) & $14.6 \pm 4.3$ & $14.1 \pm 4.3$ & $12.2 \pm 3.4$ & .02 \\
\hline
\end{tabular}


TABLE E2. Continued

\begin{tabular}{|c|c|c|c|c|}
\hline Variable & $\begin{array}{l}\text { No RHF } \\
(\mathrm{n}=119)\end{array}$ & $\begin{array}{l}\text { RHF without RVAD } \\
(\mathbf{n}=45)\end{array}$ & $\begin{array}{l}\text { Need for RVAD } \\
\quad(\mathbf{n}=\mathbf{3 0})\end{array}$ & $P$ value* \\
\hline Severe tricuspid regurgitation & $40(33.6)$ & $18(40.0)$ & $15(50.0)$ & .24 \\
\hline \multicolumn{5}{|l|}{ Load adaptation indices } \\
\hline $\mathrm{RV}$ area change:RV end-systolic area & $0.34 \pm 0.14$ & $0.28 \pm 0.10$ & $0.28 \pm 0.11$ & .01 \\
\hline Diastolic Dandel index $\dagger$ & $33.10 \pm 12.23$ & $24.62 \pm 7.53$ & $27.27 \pm 8.41$ & $<.001$ \\
\hline Systolic Dandel index $\dagger$ & $40.40 \pm 15.67$ & $28.99 \pm 8.99$ & $32.29 \pm 10.56$ & $<.001$ \\
\hline $\begin{array}{l}\text { Tricuspid annular plane systolic excursion:RV systolic } \\
\text { pressure }(\mathrm{mm} / \mathrm{mm} \mathrm{Hg}) \dagger\end{array}$ & $0.30 \pm 0.12$ & $0.29 \pm 0.09$ & $0.24 \pm 0.07$ & .06 \\
\hline $\begin{array}{l}\text { Systolic pulmonary arterial pressure:cardiac index } \\
\qquad\left(\mathrm{mm} \mathrm{Hg} \cdot \mathrm{min} \cdot \mathrm{m}^{2} / \mathrm{L}\right)\end{array}$ & $30.68 \pm 15.47$ & $30.03 \pm 11.24$ & $32.95 \pm 15.21$ & .68 \\
\hline $\begin{array}{l}\text { Mean pulmonary arterial pressure:cardiac index } \\
\quad\left(\mathrm{mm} \mathrm{Hg} \cdot \mathrm{min} \cdot \mathrm{m}^{2} / \mathrm{L}\right)\end{array}$ & $20.75 \pm 10.98$ & $20.37 \pm 8.10$ & $22.33 \pm 10.38$ & .70 \\
\hline Pulse pressure:right atrial pressure & $3.58 \pm 2.89$ & $3.25 \pm 3.67$ & $2.27 \pm 1.48$ & .09 \\
\hline Mean pulmonary arterial pressure:right atrial pressure & $4.27 \pm 2.95$ & $4.04 \pm 4.11$ & $2.90 \pm 1.63$ & .10 \\
\hline
\end{tabular}

Values are presented as mean \pm standard deviation or $\mathrm{n}(\%)$. Bold indicates $P<.05 . R H F$, Right heart failure; $R V A D$, right ventricular atrial assist device; INTERMACS, Interagency Registry for Mechanically Assisted Circulatory Support; $M D R D$, Modification of Diet in Renal Disease equation; $R V$, right ventricular. $* P$ value of 1-way analysis of variance or $\chi^{2}$ test. $\dagger$ The tricuspid regurgitation Doppler envelope was interpretable in $82 \%$ of patients, enabling determination of these indices.

TABLE E3. Univariate logistic regression analysis of correlates of clinical right heart failure after left ventricular assist device implantation, excluding patients requiring a right ventricular assist device implantation (occurring in 45 out of 164 patients)

\begin{tabular}{|c|c|c|c|}
\hline Variable & $\frac{\text { Unadjusted (per unit change) }}{\text { OR }(95 \% \mathrm{CI})}$ & $\frac{\text { Adjusted (per SD change) }}{\text { OR }(95 \% \text { CI)* }}$ & $P$ value \\
\hline Age per unit or SD decrease (y) & $0.98(0.95-1.01)$ & $0.77(0.52-1.03)$ & .07 \\
\hline INTERMACS profiles $\dagger$ & $1.77(1.22-2.58)$ & - & $<.01$ \\
\hline Right atrial pressure per unit or SD increase ( $\mathrm{mm} \mathrm{Hg}$ ) & $1.04(0.99-1.09)$ & $1.32(0.94-1.84)$ & .10 \\
\hline $\mathrm{RV}$ end-systolic area index per unit or SD increase $\left(\mathrm{cm}^{2} / \mathrm{m}^{2}\right)$ & $1.24(1.11-1.38)$ & $2.16(1.45-3.18)$ & $<.001$ \\
\hline RV longitudinal strain per unit or SD worsening & $1.16(1.04-1.29)$ & $1.76(1.16-2.63)$ & $<.01$ \\
\hline \multicolumn{4}{|l|}{ Interventricular ratios } \\
\hline $\begin{array}{l}\text { Right atrial pressure:pulmonary arterial wedge pressure per } \\
\text { unit or SD increase }\end{array}$ & $3.02(0.66-13.89)$ & $1.28(0.91-1.78)$ & .16 \\
\hline $\begin{array}{l}\text { Mean pulmonary arterial pressure:mean arterial pressure per } \\
\text { unit or SD increase }\end{array}$ & $7.01(0.73-67.05)$ & $1.34(0.95-1.88)$ & .09 \\
\hline \multicolumn{4}{|l|}{ Ventriculoarterial coupling } \\
\hline $\mathrm{RV}$ area change:RV end-systolic area per unit or SD decrease & $34.48(1.74-1000)$ & $1.58(1.07-2.45)$ & .02 \\
\hline \multicolumn{4}{|l|}{ Physiological indices } \\
\hline Diastolic Dandel's index per unit or SD decrease $\ddagger$ & $1.11(1.05-1.17)$ & $3.38(1.77-6.26)$ & $<.001$ \\
\hline Systolic Dandel's index per unit or SD decrease $\downarrow$ & $1.09(1.05-1.14)$ & $3.62(2.07-7.08)$ & $<.001$ \\
\hline \multicolumn{4}{|l|}{ Ratio metrics } \\
\hline $\begin{array}{l}\text { Tricuspid annular plane systolic excursion:RV systolic } \\
\text { pressure per unit or SD decrease }(\mathrm{mm} / \mathrm{mm} \mathrm{Hg}) \ddagger\end{array}$ & $2.02(0.06-66.67)$ & $1.08(0.73-1.59)$ & .69 \\
\hline $\begin{array}{l}\text { Systolic pulmonary arterial pressure:cardiac index per unit or } \\
\text { SD increase }\left(\mathrm{mm} \mathrm{Hg} \cdot \min \cdot \mathrm{m}^{2} / \mathrm{L}\right)\end{array}$ & $0.99(0.97-1.02)$ & $0.87(0.64-1.33)$ & .80 \\
\hline $\begin{array}{l}\text { Mean pulmonary arterial pressure:cardiac index per unit or } \\
\text { SD increase }\left(\mathrm{mm} \mathrm{Hg} \cdot \min \cdot \mathrm{m}^{2} / \mathrm{L}\right)\end{array}$ & $0.99(0.96-1.03)$ & $0.90(0.66-1.35)$ & .83 \\
\hline Pulse pressure:right atrial pressure $<2.0$ & $2.32(1.13-4.77)$ & - & .02 \\
\hline Mean pulmonary arterial pressure:right atrial pressure $<2.5$ & $2.03(0.96-4.31)$ & - & .07 \\
\hline
\end{tabular}


TABLE E4. Univariate logistic regression analysis of correlates of composite right ventricular assist device need or clinical right heart failure after left ventricular assist device implantation (occurring in 75 out of 194 patients)

\begin{tabular}{|c|c|c|c|}
\hline Variable & $\frac{\text { Unadjusted (per unit change) }}{\text { OR }(95 \% \mathrm{CI})}$ & $\frac{\text { Adjusted (per SD change) }}{\text { OR }(95 \% \mathrm{CI})^{*}}$ & $P$ value \\
\hline Age per unit or SD decrease (y) & $0.98(0.95-0.99)$ & $0.77(0.51-0.96)$ & .03 \\
\hline INTERMACS profiles $\dagger$ & $1.92(1.39-2.63)$ & - & $<.001$ \\
\hline Right atrial pressure per unit or SD increase $(\mathrm{mm} \mathrm{Hg})$ & $1.06(1.02-1.11)$ & $1.51(1.15-2.08)$ & $<.01$ \\
\hline RV end-systolic area index per unit or SD increase $\left(\mathrm{cm}^{2} / \mathrm{m}^{2}\right)$ & $1.23(1.12-1.35)$ & $2.11(1.50-2.95)$ & $<.001$ \\
\hline RV longitudinal strain per unit or SD worsening & $1.18(1.06-1.30)$ & $1.75(1.23-2.50)$ & $<.01$ \\
\hline \multicolumn{4}{|l|}{ Interventricular ratios } \\
\hline $\begin{array}{l}\text { Right atrial pressure:pulmonary arterial wedge pressure per unit or SD } \\
\text { increase }\end{array}$ & $5.14(1.38-19.11)$ & $1.46(1.08-1.97)$ & .02 \\
\hline $\begin{array}{l}\text { Mean pulmonary arterial pressure:mean arterial pressure per unit or SD } \\
\text { increase }\end{array}$ & $0.92(0.81-1.03)$ & $1.01(1.00-1.03)$ & .15 \\
\hline \multicolumn{4}{|l|}{ Ventriculoarterial coupling } \\
\hline $\mathrm{RV}$ area change: $\mathrm{RV}$ end-systolic area per unit or SD decrease & $43.48(3.38-500)$ & $1.64(1.18-2.22)$ & $<.01$ \\
\hline \multicolumn{4}{|l|}{ Physiologic indices } \\
\hline Diastolic Dandel's index per unit or SD decrease $\ddagger$ & $1.09(1.04-1.14)$ & $2.56(1.59-4.17)$ & $<.001$ \\
\hline Systolic Dandel’s index per unit or SD decrease $\ddagger$ & $1.08(1.04-1.11)$ & $2.86(1.79-4.55)$ & $<.001$ \\
\hline \multicolumn{4}{|l|}{ Ratio metrics } \\
\hline $\begin{array}{l}\text { Tricuspid annular plane systolic excursion:RV systolic pressure per unit } \\
\text { or SD decrease (mm/mm } \mathrm{Hg}) \ddagger\end{array}$ & $12.5(0.50-333)$ & $1.28(0.93-1.79)$ & .12 \\
\hline $\begin{array}{l}\text { Systolic pulmonary arterial pressure:cardiac index per unit or SD increase } \\
\left(\mathrm{mm} \mathrm{Hg} \cdot \mathrm{min} \cdot \mathrm{m}^{2} / \mathrm{L}\right)\end{array}$ & $1.01(0.98-1.02)$ & $1.03(0.75-1.33)$ & .81 \\
\hline $\begin{array}{l}\text { Mean pulmonary arterial pressure:cardiac index per unit or SD increase } \\
\left(\mathrm{mm} \mathrm{Hg} \cdot \mathrm{min} \cdot \mathrm{m}^{2} / \mathrm{L}\right)\end{array}$ & $1.01(0.98-1.03)$ & $1.04(0.81-1.35)$ & .79 \\
\hline Pulse pressure:right atrial pressure $<2.0$ & $2.68(1.45-4.95)$ & - & $<.01$ \\
\hline Mean pulmonary arterial pressure:right atrial pressure $<2.5$ & $3.05(1.62-5.75)$ & - & $<.01$ \\
\hline
\end{tabular}

Bold indicates $P<.05$. SD, Standard deviation; $O R$, odds ratio; $C I$, confidence interval; INTERMACS, Interagency Registry for Mechanically Assisted Circulatory Support; $R$, right ventricular. $*$ ORs are presented as OR per SD increase or decrease for continuous variables and calculated as OR ${ }^{\mathrm{SD}}$ per risk. $\dagger$ Using INTERMACS $\geq 4$ as the reference group. $\ddagger$ The tricuspid regurgitation Doppler envelope was interpretable in $82 \%$ of patients, enabling determination of these indices. 